\title{
Transposition of modus operandi from the real to the virtual using several signatures: Case of "the drowned of the Garonne" serial crimes in France
}

\author{
Nadine Touzeau* \\ Profiler, Net-profiler, Researcher in Behavior of cybercriminals, Paris, France
}

\begin{abstract}
This research is about a case I worked on in 2013 in France, a case that was related to terrorism. In fact, I discovered a peculiarity in the use of dark web on criminal cases and illicit trafficking networks. This, thanks to the use of the three theories I have developed to explain the differentiation between the real and virtual spaces with regard to human behaviors. In my recent article (Touzeau [1]), I have talked about these theories which are "Avatarisation", "Transverse Zone" and "Virtual Intelligence" confirmed all by many results I obtained on the ground. The review of my book (Touzeau [2]) pointed to cybercriminal acts, be they cyberbullying, President's scam, malware intrusion, ransomware, sextape, phishing or terrorism to explain how crime signatures can be duplicated.

The use of the dark web made possible the dissemination of information on crimes in the darknet, some of which with homicides and crimes that have been reproduced in the real world but with some differences. My research conclusion was that modus operandi can be broadcasted via the darknet with a report by other individuals using several signatures. The present paper focuses on « Les noyés de la Garonne » (The drowned of the Garonne) famous case in France and widely published to explain the complexity in cybercriminal investigations since the virtual space permits behavioural differentiations and allows crime duplication by authors other than the crime initiator.
\end{abstract}

\section{Introduction}

A case of homicide being elucidated was proposed to me in order to reproduce the last hours of a young man life found drowned in the Garonne. This famous case in France [3] has prompted questions beyond the Atlantic as a result of the hypotheses and conclusions I made. This case was not unique: other homicides of this nature spread throughout France. The modus operandi with a lot of similarity: a man who disappeared from the effects of an evening with friends in discotheque or other festive places. Media coverage was more focused on these young men who were found drowned in a river, lake or other important natural water sources.

Of the first cases studied, these men were all alcoholised above legal authorization. What the press seldom mentioned, were the other cases of these men who found themselves 24 hours after a festive evening in an unknown universe, or not foreseen in their program. All these victims, whether they were alive or not, experienced the same things and had the same symptoms. The victims had all been drugged by a drug that was not sufficiently identified at that time, but which the Forensic Doctor, with whom I was working, defined as a mixture of LSD and GHB with elements of the "rapist's drug". The victims remembered nothing, behaved like they were drugged, lost their orientation. In the hours that followed, they all had quite severe stomach pains. We didn't find anything in common with the victims. That being said, I was only able to work on one case and skim the others in progress, not the next ones. All the victims were stripped of their credit card with their empty bank account. Considering that it was necessary to know their credit card code to withdraw money from the cash machine. And all the victims were smokers, sometimes occasional drug addicts. In another case, the victim had undergone the same modus operandi six months before his death and with the same symptoms. We suspected that when he was drugged and unaware of his whereabouts, his phone was hacked into to steal data that was used to kill him. In fact, we considered that there were two motives of the murderer: the first was to drug his target to steal his money. The second was to test new forms of chemical drugs.

\section{Discussion}

What allowed us to come to the conclusion that there were two motives, first was the composition of the drugs unknown in the French market at that time, and second, the theft of bank cards with money robbery from their victims' accounts. However, we did not understand, at first, why these procedures were being replicated in other cities in France. The alcoholic victims disappeared after a nightclub outing, late at night. Their friends did not pay attention to their release. Very often, it is the next day of the disappearance that the body is found in a water point. Thus, because the victims are smokers and alcoholics, investigators and the justice system tended not considering a consumption of a chemical drug too. For them, the victims fell in the water after drinking too much losing the control of their behaviors and awareness. How could the victims have been drugged? Was it by a cigarette offered or a wine poured into their glass? The problem we encountered when confronted

${ }^{\star}$ Correspondence to: Nadine Touzeau, Profiler, Net-profiler, Researcher in Behaviour of Cybercriminals, Paris, France, E-mail: nt.profiler@gmail.com

Key words: crime, behavioral differentiation, real and virtual spaces, net-profiling, modus operandi, signatures, cybercriminals

Received: February 13, 2018; Accepted: February 20, 2018; Published: February 24,2018 
with the refusal of investigators and justice to consider that these victims could have been drugged without realizing it, was that of finding an evidence, a good one. So, we found one about the victim "Noyé de la Garonne" (The drowned of the Garonne) by analyzing the videos and re-interviewing witnesses. We found that the victim was unable to pick up her fallen lighter. We also noticed that the behavior of this alcoholic person was rigid as he stooped down to try to catch his lighter. He could not bend down, bow his head to the ground or bend his knees, but only try to bend down while being stiff. The Forensic Doctor concluded that it could not be alcohol or a conventional drug. The young victim's behavior, later analyzed on the videos, showed his stomach ache that accentuated his disorientation. These elements were given as evidence that the victim was drugged without his knowledge by a chemical drug causing him to lose his means, his marks and making him sick from the stomach. By cross-checking the information, we found that the other victims in France have known similar stories. In fact, the investigators felt that it was necessary to trace a schedule in order to track suspects traveling to France. I could not believe this hypothesis because these cases had only similarities, but not enough synergies between hem to consider that it was a single person traveling in France. Between all the cases, the differences noted were just few ones: the estimated time of disappearance was not the same, the profiles, although males ranged from 20 to 45 years of age, the social levels were different, the physical level was different, even if they were all European, the victims did not wake up in a similar place. These differences highlighted signatures that could support a conclusion of the case on a raging network, with the possibility those members of that network might move geographically. The question that came to the conclusion of my hypothesis was: but why did the members of this network make so many different signatures among themselves? It was there, when I decided to look at the cybercriminal probability. The analysis made it possible to consider an operating mode indicated to potential disciples who reproduced it in the real world. This could explain why the signatures were so different. After investigations, this hypothesis was found to be correct, even though the investigators and the judiciary ignored it. Robert Kepper [4] argued that there are two fundamental criteria for defining the profile of a criminal: his signature and his modus operandi. The murderer's signature is an element of the perpetrator's specific crime scene. The modus operandi refers to the murderer's specific methods. The modus operandi can change, not the signature. It is on these elements that my hypothesis concludes that it was a modus operandi duplicated using the darkweb so that it could be reproduced in reality by other murderers. This explains why the signatures were different.

\section{Conclusion}

The majority of crimes in the real space have been transposed to the virtual one. However, homicides are not common in virtual space. Still, the dark web allows illegal or unauthorized information to be distributed in real space: A modus operandi. The later can be used to feed a network by money robbery using bank cards. It also can be used to encourage other trafficking and the spread of chemical drugs. This blurs the tracks when focusing on the real space while all information is spread through the virtual one. Several cases since then have revealed this process such as the Islamic State's terrorists who spread through the dark web many projects, success stories and even needs, to set up their action in the real world. In Europe, for example, knife attacks by terrorists had similarities, particularly in the modus operandi of different signatures. Other attacks such as rams also have the same modus operandi with several different signatures. In 2015, Jared Cohen [5] declared: "Daech also makes extensive use of the dark web channels for all its operational communications, its revolutionary tax and donation collections or even for discreetly tampering." Synergies do not happen between these cases. Yet, elements in the darknet have proven that synergy exists. Investigations had to consider synergies even between perpetrators of terrorist acts who, most often, knew each other virtually. Behavioural analyses in the real and virtual spaces made possible to understand that acts committed in the real world guided by indications and success stories coming from the virtual space. Knowing that the virtual could not indicate all the elements of implementation in the real world, authors on the other hand must share the same goals, convictions and objectives in order to reproduce a modus operandi. These collected elements made possible to make profiles by mixing both analyses, in the real and virtual by using profiling and net profiling. Unfortunately, even today, and particularly on terrorist issues, cybercrime (including cyberterrorism) is not sufficiently involved in investigations. They are effectively truncated in front of offenders who know how to use the cyber means to cover their tracks and work more easily.

\section{References}

1. Touzeau N (2017) Behavioral Cybercriminals Differentiations between the Real World and the Virtual Space. J Foren Res 8: 401.

2. Touzeau N (2015) Net-profiling: analyse comportementale des cybercriminels https://www.amazon.fr/NET-PROFILINGcomportementale-cybercriminels-NadineTouzeau/dp/2955453730.

3. Les noyés de la Garonne: Criminal case, managed by an ex French police officer who worked with profilers in Canada.

4. Robert David Keppel, is a retired American law enforcement officer and detective best known for his work investigating serial killers Ted Bundy and Gary Ridgway.

5. Jared COHEN (born November 24, 1981) is the CEO of Jigsaw (previously Google Ideas) and an Adjunct Senior Fellow at the Council on Foreign Relations

Copyright: (C2018 Touzeau N. This is an open-access article distributed under the terms of the Creative Commons Attribution License, which permits unrestricted use, distribution, and reproduction in any medium, provided the original author and source are credited. 